\title{
A subtle pedagogy: a response to Megan Laverty
}

\author{
Sharon Todd* \\ Stockholm University, Stockholm, Sweden
}

Before I begin, I wish to thank Megan Laverty for what I see as a gracious paper, one that opens up some difficult questions for education while allowing room for hope to pursue the task in which all of us are engaged in our daily lives. Laverty has undertaken here a kind of instruction of sorts. She states the importance of what she calls instructional scepticism for the field of philosophy of education, and for the practice of education more generally. Her instruction entails a commitment to the project of education through the acknowledgement of its paradoxes and its impossibilities. Casting a Deweyan eye over the educational landscape, Laverty concentrates on the active, social nature of what it is we do in schools and classrooms. Her view builds upon an initial tracing of conceptual differences within the field of philosophy of education, based on the 'call to be practical' and in so doing refuses to reassert the very tired divisions between analytic and continental philosophy and between modern rationalism and poststructuralism. Terms, which to my mind, are practically useless and theoretically flawed, as they only serve to stifle thought as opposed to opening up the ground for new questioning. Laverty instead redefines the call to be practical in such a way as 'to make explicit the ethical, aesthetic, and existential dimensions of education' (p. 44).

To do so, Laverty returns to the Western pedigree of the idea of the impossibility of instruction, and presents us with some pretty sturdy 'book-ends': Plato and Wittgenstein. She draws an important distinction between them, addressing their reasoning behind the impossibility of instruction. For Plato, teaching is impossible because learning is impossible; for Wittgenstein, learning is impossible because teaching is impossible. Through both she puts forth the idea that even though there is an inherent impossibility at the core of the instructional endeavour, there is nonetheless a certain compulsion to pursue the task of instruction - a compulsion that embraces the idea that the value of instruction lies not in the perfection of humanity but in the fact that it 'expresses our humanity' (p. 50).

What I want to comment on here largely is the language in which Laverty seeks to shift the terms of engagement from education - and even teaching and learning - to instruction. I will be attending to what I see is the key impetus to this move, and suggest that what Laverty is getting at through her use of the term instruction is the idea of a 'subtle pedagogy' - a pedagogy that reflects the complex dynamics, relations and indeed mystery, as Laverty herself puts it, attendant upon the practice of teaching and learning. In doing so I draw some inspiration from an alternative 'historic core' to that of the Western philosophical one - i.e. the yoga tradition.

\footnotetext{
*Email: Sharon.todd@edu.su.se
} 


\section{A subtle pedagogy}

The term 'instructional scepticism' can be read, as Laverty intends, as a kind of scepticism focused on the topic of instruction. However, it can also be read as scepticism having instructional value. And although this is not the overt meaning Laverty has in mind, I think much of what she says about the import of thinking 'queerly', i.e. through the paradoxes of the instructional context, is indeed a kind of scepticism that is instructional for all of us.

Although initially Laverty paints a very anglo-centred view of the field of philosophy of education as an academic discipline forged in the post-war era (in contradistinction to European traditions of bildung, for example, that pre-date this by a few hundred years), she nonetheless leaves this behind to explore the very difficulties of pedagogy that many philosophers of education have ignored: that of the impossibility of instruction.

Reading education initially as something that happens to us and as something that we do, Laverty insists that the term itself is inadequate to the kind of activity present in classroom, and presumably other, educational settings. In this sense, there is a real Deweyan sensibility in this text, with a focus on words such as action, doing, task and experience. Indeed, Laverty chooses instruction as a term because it 'implies a task' as opposed to education, which 'implies achievement' (p. 46).

What Laverty suggests is that we reframe our attention to the work of schools as instruction, and instead of using the distinct terms of teaching and learning, she champions the idea that we need to attend to the task of instruction as an activity that leaves open the questions of teaching of learning. That is, she wishes to emphasise the importance of what Derrida would call the 'undecidability' of the event; the openness to what might happen because it is an activity that cannot be fully captured in the lexicon of outcomes and performativity.

The suggestion here is that the term instruction is better because it highlights the shared activity of teaching-learning, implying that it is the social, communicative element of the relation in which our humanity is expressed. I am very sympathetic to this view, but the same issues remain, it seems to me, with instruction as with teaching and learning: instruction implies a two-sided activity: instructing and being instructed. There is no symmetry to this relation; the 'being' instructed still places the person in an existential mode - if not a subordinate one - in relation to the one who is 'doing' instruction. The active verb to instruct only applies to the instructor, not the instructee. In some sense the one who 'is' instructed does not seem to me to fair much better than if she were a learner exposed to the demands of teaching. So the shift from the language of teaching and learning does not shift, in my view, the pedagogical dynamics at stake in the relation itself. That is, if we focus our attention on the activity of instruction, we are still confronted with asymmetry (as well as the paradoxes, as Laverty keenly points out) between those who are instructing and those who are being instructed. Now, while it is certainly the case that I, as one engaged in instruction in my role as a teacher, can also be instructed as I 'do' instruction - about the actual subject I teach, about the limits of my role as teacher, about the relationship with the student; yet I do so from a different vantage. This is not due to some basic inequality which slots humans into hierarchies of intelligence (the teacher is more intelligent or is in possession of more intelligence than the student) but to a perspectival difference occasioned by the economy of the instructional exchange - an economy which is complexly interwoven with existential singularity (I am not you), individual passions, personal commitments, community expectations and social norms. 
That is, although the activity of instruction involves at least two persons, it not only involves them differently, but it does so in ways that are neither predictable nor controllable, for the reasons just named.

Now I think Laverty is suggesting that it is precisely this aspect of pedagogy that is at stake when she writes that 'instruction expresses our humanity'. Citing Todorov, Laverty notes that 'instruction occasions small acts of will that dignify others' (p. 47). That is, instruction contains within it the possibility to exercise a graciousness and generosity towards others, but it also contains, following this logic, the desires, passions and fears which can also disrupt even the most well-intended and benevolent of teachings. What instruction occasions is therefore a complex interplay between singular persons, men and women, and between persons and subject matter, who each have their own histories and experiences brought to bear on the educational encounter. It is this dynamic interplay, moreover, that Laverty claims as being crucial for enriching our discussions in our own field, and has practical implications for how we approach schooling. It opens up, as she suggests, the questions of teaching and learning, in the sense these can never be final or closed, but must remain open to continual examination.

What I remain uncertain of here is whether we need to shift to a language of instruction, with all its 'technical' sounding connotations in order to get to this sphere of educational experience. Instruction, for example, is often used - although obviously not exclusively - when the knowledge to be acquired is more skill related: driving instructor, gym instructor and ski instructor. I am wondering if we might just name this sphere of complex interplay; give it a term that lets some of this seemingly ineffable stuff that floats between and among us in educational settings come into the open. For if it is this dynamic aspect of instruction that Laverty is calling into being with her emphasis on instruction as an expression of humanity, then perhaps we need to address it more directly. To this end, it is precisely this aspect that I wish to call 'subtle pedagogy'.

The term subtle in the yogic tradition is used in relation to the body to denote the somatic energies that affect both physical and mental well-being. They are not to be found in an X-ray of the body, but are experiential in nature, and have to do with how the body and mind function together to create different states of being. Subtle does not mean slight or delicate in this context, but rather is something not available to immediate perception. Subtle pedagogy is not about the overt activity of instruction (or teaching and learning), i.e. that which is measurable, standardisable and evaluative, but it nonetheless shapes the kinds of attitudes, fears, dislikes and loves that accompany teaching and learning. Like the subtle body of yoga, we cannot hope to X-ray classrooms and 'see' the subtle dimensions of experience that make up classroom life, nor can we capture them through other imaging techniques or technologies of assessment. They remain, in other words, outside our normalised purview - outside, that is, if we build education only upon that which is tangible, subject to direct perception and measurability. But to give these experiences a name, to designate them and nominate them is to bring them into our field of attention, even if we cannot directly see them. That is, it requires another kind of seeing - one, it seems to me, that is crucial for beginning to take the qualitative and not just the quantitative aspects of pedagogy seriously. For does not a commitment to education arise out of the (perhaps tacit) acknowledgement that something happens qualitatively to us who enter into instructional settings?

The Sanskrit word, darshana, is helpful here as it refers to seeing in both a literal and metaphorical sense, and denotes a philosophy or worldview. When we start to take what 
Laverty calls 'instructional scepticism' seriously, when we start to acknowledge the 'subtle pedagogy', we start to develop a different philosophy of education - an education darshana. This means 'seeing' what it is schools do differently, a way of recognising the messiness that sometimes leads to love of a subject, a way of recognising what is there but not spoken. This reintroduces, as Laverty suggests, a sense of mystery into a sphere that to my mind has been robbed of its singularity, its human faces, in the never-ending drive to package, standardise and numerically evaluate knowledge. Through this other darshana, we might just begin to hear again words such as wisdom, presence and insight as part of a commitment to education. And on this point especially, Megan and I are, I venture to say, in total agreement. 